\title{
Fuzzy Goal Programming Procedures for Multi-Level Multi-Objective Linear Fractional Programming Problems
}

\begin{abstract}
Ibrahim A. Baky
Abstract

This paper presents two fuzzy goal programming (FGP) procedures for solving multi-level multiobjective linear fractional programming (ML-MOLFP) problems.

In the proposed procedures, the membership functions for the defined fuzzy goals of all objective functions at all levels as well as the membership functions for vectors of fuzzy goals of the decision variables, controlled by decision makers at the top levels, are developed in the model formulation of the problem. Then fuzzy goal programming approach is used to achieve highest degree of each of the membership goals by minimizing their deviational variables and thereby obtaining the most satisfactory solution for all decision makers.

The first proposed FGP procedure makes an extension work of Pramanik and Roy [23] and of B.B. Pal et al. $[17,20]$. The second proposed procedure my be seem as lexicographic methods for solving multiobjective programming problems that follows Shih et al. concept [28] but by using the FGP approach.

The method of variable change on the under- and over-deviational variables of the membership goals associated with the fuzzy goals of the model is introduced to solve the problem efficiently by using linear goal programming (LGP) methodology. Illustrative numerical example is given to demonstrate the algorithms.
\end{abstract}

Keywords: Multi-Objective Linear Fractional Programming; Multi-Level Programming Problems; Goal Programming; Fuzzy Mathematical Programming; Fuzzy Goal Programming.

\section{Introduction}

Multi-level mathematical programming (MLP) is defined as mathematical programming that solves decentralized planning problems with multiple decision makers (DMs) in a multi-level or hierarchical organization [28]. The basic concept of the MLP technique is that the first-level decision maker (FLDM) sets his/her goal and/or decision, then asks each subordinate levels of the organization for their optima which are calculated in isolation. The lower level DMs' (LLDMs) decisions are then submitted and modified by the FLDM in consideration of the overall benefit for the organization. The process continues until a satisfactory solution is reached.

Most of the developments in MLP problems focus on bi-level linear programming as a class of MLP [5, 9, 7, 24]. Bi-level non-linear programming was studied in [4,6]. In [26], an interactive algorithm for bi-level multi-objective programming was presented and explained using the concept of satisfactoriness. Bi-level multi-objective with multiple interconnected decision makers was discussed in [27]. Three-level programming (TLP) is another class of MLP problems in which there are three independent decision-makers (DMs) $[14,19]$. Each DM attempts to optimize its objective function and is affected by 
Military Technical College

Kobry Elkobbah,

Cairo, Egypt

May 29-31,2012

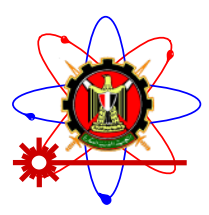

$6^{\text {th }}$ International Conference

on Mathematics and

Engineering Physics

(ICMEP-6)

the actions of the other DMs. Several three-level programming problems along with their solution methods were studied and introduced, such as the hybrid extreme-point search algorithm [9,15], mixed-integer problem with complementary slackness [14], and the penalty function approach [6,14]. A bibliography of the related references on bi-level and multi-level programming in both linear and non-linear cases, which is updated biannually, can be found in [32]. The use of the fuzzy set theory [33] for decision problems with several conflicting objectives was first introduced by Zimmermann [34] Thereafter, various versions of fuzzy programming (FP) have been investigated and widely circulated in literature [14, 15, 16, 17,20,29]

In a hierarchical decision making context, it has been realized that each DM should have a motivation to cooperate with other, and a minimum level of satisfaction of the DM at a lower-level must be considered for overall benefit of the organization. The use of the concept of membership function of fuzzy set theory to multi-level programming problems for satisfactory decisions was first introduced by Lai [13] in 1996. Thereafter, Lai's satisfactory solution concept was extended by Shih et al. [28] and a supervised search procedure with the use of max-min operator of Bellman and Zadeh [8] was proposed. Abo-Sinna $[4,19]$ extended the fuzzy approach for multi-level programming problems of Shih et al. [28] for solving bi-level and three-level non-linear multi-objective programming problems. The basic concept of these fuzzy programming (FP) approaches is the same as implies that each lower levels decision makers optimizes his/her objective function, taking a goal or preference of the first level decision makers into consideration. In the decision process, considering the membership functions of the fuzzy goals for the decision variables of all the decision makers solves a FP problem with a constraint on an overall satisfactory degree of any upper levels. If the proposed solution is not satisfactory to any upper levels, the solution search is continued by redefining the elicited membership functions until a satisfactory solution is reached [17, 21].

The main difficulty arises with the FP approach of Shih et al. is that there is possibility of rejecting the solution again and again by the FLDM and re-evaluation of the problem is repeatedly needed to reach the satisfactory decision, where the objectives of the DMs are over conflicting. Even inconsistency between the fuzzy goals of the objectives and the decision variables may arise. This makes the solution process a lengthy one [17, 21]. The fuzzy goal programming (FGP) technique introduced by Mohamed [16] - for proper distribution of decision powers to the DMs to arrive at a satisficing decision for overall benefit of the organization - was developed to overcome the above undesirable situation. These advantages of FGP approach indicate the strength of the use of the FGP approach compared to other approaches. The FGP of Mohamed [16] was extended to solve multiobjective linear fractional programming problems in [20], bi-level programming problems in [17], bi-level quadratic programming problems in [21], and in [23] a fuzzy goal programming approach to multi-level programming problems, with a single objective function in each level, is extended. 
Military Technical College

Kobry Elkobbah,

Cairo, Egypt

May 29-31,2012

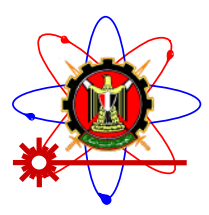

$6^{\text {th }}$ International Conference

on Mathematics and

Engineering Physics

(ICMEP-6)

In this article, the fuzzy goal programming (FGP) approach introduced by Mohamed [16] is extend to solve multi-level multi-objective linear fractional programming (ML-MOLFP) problems. Two FGP procedures are presented in this article to ML-MOLFP problem. To formulate any of the two proposed FGP models of the TLMOLFP problem, the fuzzy goals of the objectives are determined by determining individual optimal solutions. The fuzzy goals are then characterized by the associated membership functions which are transformed into fuzzy flexible membership goals by means of introducing over and under deviational variables and assigning highest membership value (unity) as aspiration level to each of them. To elicit the membership functions of the decision vectors controlled by any level DM, the optimal solution of the corresponding MOLFP problem is separately determined. A relaxation of the decisions are considered to avoid decision deadlock.

The first proposed FGP procedure makes an extension work of B.B. Pal et al. [17,20] and of Pramanik and Roy [23]. B.B. Pal et al. deals in [17] with bi-level linear single objective programming problems, and deals with single level multiobjective linear fractional programming (MOLFP) problems in [20]. In [23], Pramanik and Roy propose a FGP procedure to multi-level programming problems, with a single linear objective in each level. The final fuzzy model of Pramanik and Roy groups the membership functions for the defined fuzzy goals of the objective functions at all levels as well as the membership functions of the fuzzy goals of the decision variables, which evaluated separately, for each level except the lower level of the multi-level problem.

The second proposed procedure my be seem as lexicographic methods for solving multiobjective programming problems. Firstly, formulates the FGP model of the first level problem obtaining the satisfactory solution of FLDM problem. A relaxation of the FLDM decisions is considered to avoid decision deadlock. This decisions of the FLDM are modeled by membership functions of fuzzy set theory and passed to the SLDM as additional constrains. Then, the SLDM formulates its FGP model that takes into consideration the membership goals of the objectives and decision variables of the FLDM. Thereafter, the attained solution is sent to the TLDM who seeks the solution in a similar manner. The process continuous until the lower level. This procedure may be considered as extension of the fuzzy mathematical programming algorithm of Shih et al. concept [28] that modified by Sinha in [29,30] following the FGP approach of Mohamed [16].

The method of variable change on the under- and over-deviational variables of the membership goals associated with the fuzzy goals of the model is introduced to solve the problem efficiently by using linear goal programming (LGP) methodology.

\section{Problem Formulation}

Consider a P-level programming problem of minimization-type multi-objective functions at each level. Let $\mathrm{DM}_{\mathrm{i}}$ denote the decision maker at the $i^{\text {th }}$ level, 
Military Technical College

Kobry Elkobbah,

Cairo, Egypt

May $29-31,2012$ $6^{\text {th }}$ International Conference

on Mathematics and

Engineering Physics

(ICMEP-6)

$\boldsymbol{x}_{\mathrm{i}}, i=1,2, \ldots, p, \quad n_{i}$-dimensional decision variable, where $\boldsymbol{x}=\left(\boldsymbol{x}_{1}, \boldsymbol{x}_{2}, \ldots, \boldsymbol{x}_{p}\right) \in \mathrm{R}^{\mathrm{n}}$, $\boldsymbol{x}_{i}=\left(x_{i 1}, x_{i 2}, \ldots, x_{i n_{i}}\right) \in \mathrm{R}^{\mathrm{n}_{i}}, i=1,2, \ldots, p$, and $n=n_{1}+n_{2}+\ldots+n_{p}$. The $\mathrm{DM}_{i}$ has control over the decision variable $\boldsymbol{x}_{\mathrm{i}} \in \mathrm{R}^{\mathrm{n}_{\mathrm{i}}}, i=1,2, \ldots, p$. Furthermore, assume that:

$$
\mathrm{F}_{i}(\boldsymbol{x}): \mathrm{R}^{\mathrm{n}_{1}} \times \mathrm{R}^{\mathrm{n}_{2}} \times \ldots \times \mathrm{R}^{\mathrm{n}_{p}} \rightarrow \mathrm{R}^{\mathrm{m}_{i}}, \quad i=1,2, \ldots, p .
$$

are multi-objective functions of the $\mathrm{DM}_{\mathrm{i}}$. Mathematically, the ML-MOLFP problem of minimization type may be formulated as follows $[2,14,17,18,22,23,28]$ :

$\left[1^{\text {st }}\right.$ Level $]$

$$
\operatorname{Min}_{x_{1}} F_{1}(\boldsymbol{x})=\operatorname{Min}_{x_{1}}\left(f_{11}(\boldsymbol{x}), f_{12}(\boldsymbol{x}), \ldots, f_{1 \mathrm{~m}_{1}}(\boldsymbol{x})\right)
$$

where $\boldsymbol{x}_{2}, \boldsymbol{x}_{3}, \ldots, \boldsymbol{x}_{p}$ solves

$\left[2^{\text {nd }}\right.$ Level $]$

$$
\operatorname{Min}_{x_{2}} F_{2}(\boldsymbol{x})=\operatorname{Min}_{x_{2}}\left(f_{21}(\boldsymbol{x}), f_{22}(\boldsymbol{x}), \ldots, f_{2 \mathrm{~m}_{2}}(\boldsymbol{x})\right)
$$

where $\boldsymbol{x}_{p}$ solves

$\left[p^{\text {th }}\right.$ Level $]$

$$
\operatorname{Min}_{x_{p}} F_{p}(\boldsymbol{x})=\operatorname{Min}_{x_{p}}\left(f_{p 1}(\boldsymbol{x}), f_{p 2}(\boldsymbol{x}), \ldots, f_{p \mathrm{~m}_{p}}(\boldsymbol{x})\right)
$$

subject to

$$
\boldsymbol{x} \in \boldsymbol{G}=\left\{\boldsymbol{x} \in \mathrm{R}^{\mathrm{n}} \mid \mathrm{A}_{1} x_{1}+\mathrm{A}_{2} x_{2}+\ldots+\mathrm{A}_{p} x_{p}\left(\begin{array}{l}
\leq \\
= \\
\geq
\end{array}\right) \boldsymbol{b}, \boldsymbol{x} \geq 0, \boldsymbol{b} \in \mathrm{R}^{\mathrm{m}}\right\} \neq \boldsymbol{\phi}
$$

and $\quad f_{i j}(\boldsymbol{x})=\frac{\boldsymbol{c}_{i j} \boldsymbol{x}+\alpha_{i j}}{\boldsymbol{d}_{i j} \boldsymbol{x}+\beta_{i j}}, i=1,2, \ldots, p, j=1,2, \ldots, m_{i}$

where $\boldsymbol{G}$ is the multi-level convex constraints feasible choice set, $\mathrm{m}_{i}, i=0,1,2, \ldots, p$, are the number of $\mathrm{DM}_{i}$ 's objective functions, $\mathrm{m}$ is the number of the constraints, $\mathrm{A}_{\mathrm{i}}$ are coefficients matrices of size $m \times n_{i}, i=0,1,2, \ldots, p, \boldsymbol{c}_{i j}, \boldsymbol{d}_{i j} \in \mathrm{R}^{\mathrm{n}}, \boldsymbol{d}_{i j} \boldsymbol{x}+\beta_{i j}>0 \forall \boldsymbol{x} \in \boldsymbol{G}$, and $\beta_{i j}, \alpha_{i j}$ are constants.

\section{Fuzzy Goal Programming Formulation}

In ML-MOLFP problems, if an imprecise aspiration level is assigned to each of the objectives in each level of the ML-MOLFP, then these fuzzy objectives are termed as 
Military Technical College

Kobry Elkobbah,

Cairo, Egypt

May $29-31,2012$

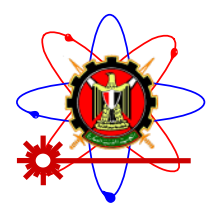

$6^{\text {th }}$ International Conference

on Mathematics and

Engineering Physics

(ICMEP-6)

fuzzy goals. They are characterized by their associated membership functions by defining the tolerance limits for achievement of their aspired levels.

\subsection{Construction of Membership Functions}

Since all the DMs are interested of minimizing their own objective functions over the same feasible region, defined by the system of constraints (3), the optimal solutions of all of them , that calculated in isolation, can be taken as the aspiration levels of their associated fuzzy goals.

Let $\boldsymbol{x}^{\mathrm{ij}}=\left(\boldsymbol{x}_{1}^{\mathrm{ij}}, \boldsymbol{x}_{2}^{i \mathrm{j}}, \ldots, \boldsymbol{x}_{p}^{i \mathrm{j}}\right) ; f_{i j}^{\min }, i=1,2, \ldots, p, j=1,2, \ldots, m_{i}$ be the optimal solutions of $\mathrm{DM}_{\mathrm{i}}$ objective functions, respectively, when calculated in isolation. Let $g_{i j} \geq f_{i j}^{\min }$ be the aspiration level assigned to the $i{ }^{\text {th }}$ objective $f_{i j}(\boldsymbol{x})$ (the subscript $i j$ means that $j=1,2, \ldots, m_{1}$ when $i=1$ for the objective functions of $\mathrm{DM}_{1}$ problem, $j=1,2, \ldots, m_{2}$ when $i=2$ for objective functions of $\mathrm{DM}_{2}$ problem, and $j=1,2, \ldots, m_{p}$ when $i=p$ for objective functions of $\mathrm{DM}_{i}$ problem). Also, let $\boldsymbol{x}^{i^{*}}=\left(\boldsymbol{x}_{1}^{i^{*}}, \boldsymbol{x}_{2}^{i^{*}}, \ldots, \boldsymbol{x}_{p}^{i^{*}}\right)$, $i=1,2, \ldots, p-1$, the optimal solution of the $i^{\text {th }}$-level MOLFP problems. Then, the fuzzy goals of the decision makers objective functions at each levels and the vector of fuzzy goals of the decision variables controlled by upper $p-1$ level decision makers are appear as:

$$
\begin{aligned}
& f_{i j}(\boldsymbol{x}) \backslash g_{i j} \quad, i=1,2, \ldots, p, j=1,2, \ldots, m_{i} \text {, and } \\
& \boldsymbol{x}_{\mathrm{i}} \overline{\bar{\square}} \boldsymbol{x}_{\mathrm{i}}^{i^{*}}, i=1,2, \ldots, p-1
\end{aligned}
$$

where " $\leq$ " and " "=" indicates the fuzziness of the aspiration levels, and is to be understood as "essentially less than" and "essentially equal to", respectively, [25,34].

It may be noted that, the solutions $\boldsymbol{x}^{\mathrm{ij}}=\left(\boldsymbol{x}_{1}^{\mathrm{ij}}, \boldsymbol{x}_{2}^{i \mathrm{j}}, \ldots, \boldsymbol{x}_{p}^{i \mathrm{j}}\right), i=1,2, \ldots, p$, $j=1,2, \ldots, m_{i}$ are usually different because the objectives of all the DMs are conflicting in nature. Therefore, it can reasonably be assumed that the values $f_{\mathbf{l} m}\left(\boldsymbol{x}_{1}^{\mathbf{1} m}, \boldsymbol{x}_{2}^{\mathbf{1} m}, \ldots, \boldsymbol{x}_{p}^{\mathbf{1} m}\right) \geq f_{i j}^{\min } \forall \mathbf{l}=1,2, \ldots, p, \quad m=1,2 \ldots, m_{i}$, and $i j \neq \mathbf{l} m$ and all values greater than $f_{\mathbf{l} m}^{u}=\max \left[f_{i j}\left(\boldsymbol{x}_{1}^{\mathbf{1} m}, \boldsymbol{x}_{2}^{\mathbf{1} m}, \ldots, \boldsymbol{x}_{p}^{\mathbf{1} m}\right), i=1,2, \ldots, p, j=1,2 \ldots, m_{i}\right.$, and $\left.i j \neq \mathbf{l} m\right]$ is absolutely unacceptable to the objective function $f_{\mathbf{l} m}(\boldsymbol{x}) \equiv f_{\mathbf{l} m}\left(\boldsymbol{x}_{1}, \boldsymbol{x}_{2}, \ldots, \boldsymbol{x}_{p}\right)$. As such, $f_{1 m}(\boldsymbol{x})$ can be considered as the upper tolerance limit $u_{1 m}$ of the fuzzy goal to the objective functions. Then, membership functions $\mu_{f_{i j}}\left(f_{i j}(\boldsymbol{x})\right)$ for the $i j^{\text {th }}$ fuzzy goal can be formulated as (Fig. 1) : 
Military Technical College

Kobry Elkobbah,

Cairo, Egypt

May $29-31,2012$ $6^{\text {th }}$ International Conference

on Mathematics and

Engineering Physics

(ICMEP-6)

$$
\mu_{f_{i j}}\left(f_{i j}(\boldsymbol{x})\right)=\left\{\begin{array}{lll}
1 & \text { if } \quad f_{i j}(\boldsymbol{x}) \leq g_{i j} \\
\frac{u_{i j}-f_{i j}(\boldsymbol{x})}{u_{i j}-g_{i j}} & \text { if } \quad g_{i j} \leq f_{i j}(\boldsymbol{x}) \leq u_{i j}, i=1,2, \ldots, p, j=1,2, \ldots, m_{i} \\
0 & \text { if } \quad f_{i j}(\boldsymbol{x}) \geq u_{i j}
\end{array}\right.
$$

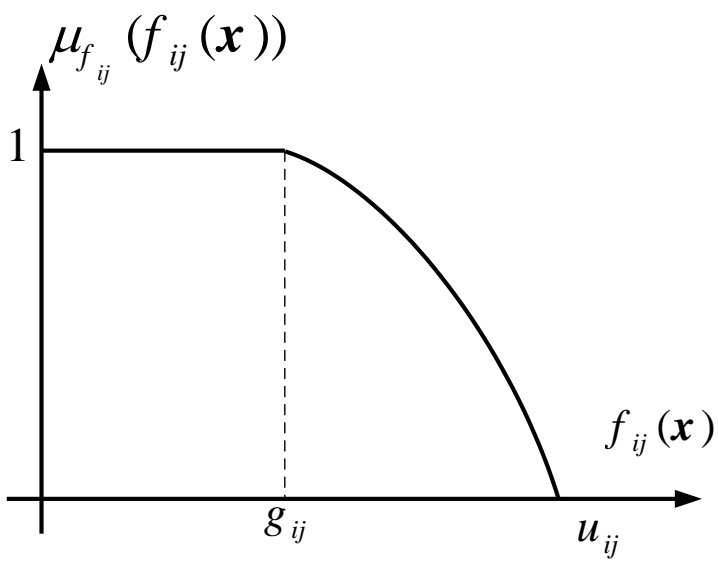

Fig 1. Membership function of minimization-type objective functions

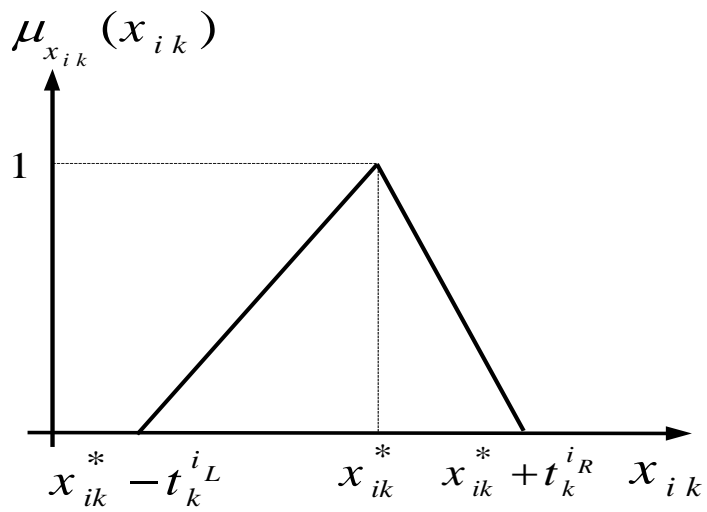

Fig 2. Membership functions of decision vectors $x_{i k}$

To build the membership functions for the fuzzy goals of the decision variables controlled by $\mathrm{DM}_{i}$, the optimal solutions of the $i^{\text {th }}$-level MOLFP problems, $\boldsymbol{x}^{i^{*}}=\left(\boldsymbol{x}_{1}^{i^{*}}, \boldsymbol{x}_{2}^{i^{*}}, \ldots, \boldsymbol{x}_{p}^{i^{*}}\right), i=1,2, \ldots, p-1$, should be determined first [10,11,12,15,20,22]. Let $t_{k}^{i_{L}}$ and $t_{k}^{i_{R}}, i=1,2, \ldots, p-1, k=1,2, \ldots, n_{i}$ be the maximum negative and positive tolerance values on the decision vectors considered by the $i^{\text {th }}$-level DM. The tolerances $t_{k}^{i_{L}}$ and $t_{k}^{i_{R}}$ are not necessarily same. These tolerances give the $i^{\text {th }}$-level DMs an extent feasible region to search for the satisfactory solution. In other words the upper level decision maker, to the $i^{\text {th }}$-level MOLFP problem, set negative and positive tolerances depend on the needs, desires and practical situations in the decision making situation. Then following the proposed algorithms, the satisfactory solution of the $i^{\text {th }}$-level MOLFP problem can be achieved. If the feasible region is empty, the negative and positive tolerances must be increased to give the $i^{\text {th }}$-level DMs an extent feasible region to search for the satisfactory solution $[17,23]$.

The linear membership functions (Fig. 2) for each of the $n_{i}$ components of decision vector $\boldsymbol{x}_{i}^{i^{*}}=\left(x_{i 1}^{*}, x_{i 2}^{*}, \ldots, x_{i n_{i}}^{*}\right)$, of $i^{\text {th }}$-level DM, $i=1,2, \ldots, p-1$, controlled by the upper $p-1$ levels decision makers can be formulated as: 
Military Technical College

Kobry Elkobbah,

Cairo, Egypt

May $29-31,2012$ $6^{\text {th }}$ International Conference on Mathematics and Engineering Physics

(ICMEP-6)

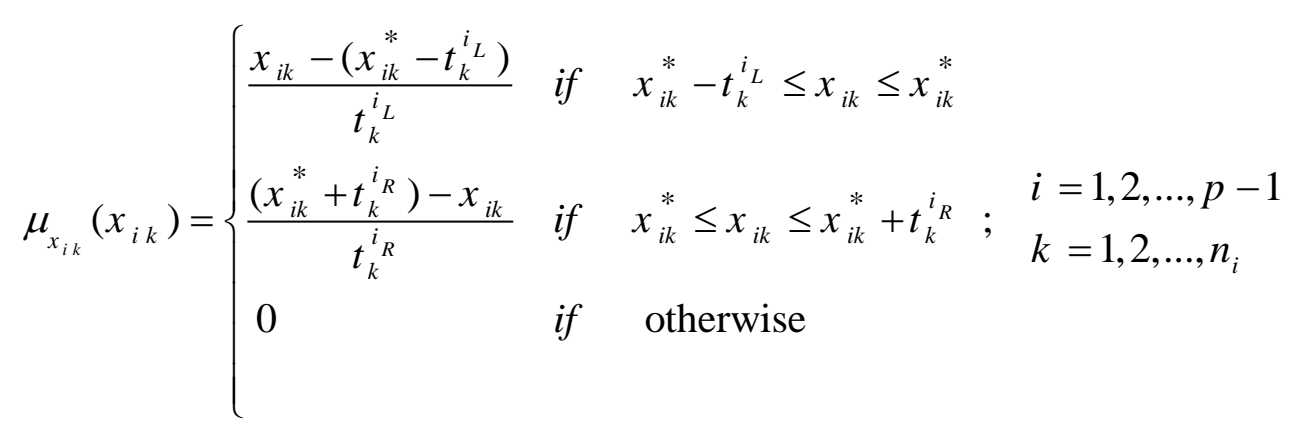

It may be noted that, the decision maker may desire to shift the range of $x_{i k}$. Following Pramanik and Roy [23] or S. Sinha [30], this shift can be achieved.

Now, in a fuzzy decision environment, the achievement of the fuzzy goals - the fuzzy goals of the decision makers objective functions at each levels and the vector of fuzzy goals of the decision variables controlled by upper $p-1$ level decision makers - to their aspired levels to the extent possible is actually represented by the possible achievement of their respective membership values to the highest degree. Regarding this aspect of fuzzy programming problems, a goal programming approach seems to be most appropriate for the solution of the upper $i^{\text {th }}$-levels multi-objective linear fractional programming problems and the multi-level multi-objective linear fractional programming problem [20].

\subsection{Fuzzy Goal Programming Approach}

In fuzzy programming approaches, the highest degree of membership function is 1. So, as in Mohamed [16], for the defined membership functions in (5) and (6), the flexible membership goals with the aspired level 1 can be presented as:

$$
\begin{array}{ll}
\mu_{f_{i j}}\left(f_{i j}(\boldsymbol{x})\right)+d_{i j}^{-}-d_{i j}^{+}=1 & i=1,2, \ldots, p, \quad j=1,2, \ldots, m_{i} \\
\mu_{x_{i k}}\left(x_{i k}\right)+d_{i k}^{-}-d_{i k}^{+}=1 & i=1,2, \ldots, p-1, k=1,2, \ldots, n_{i}
\end{array}
$$

or equivalently as:

$$
\begin{array}{ll}
\frac{u_{i j}-f_{i j}((\boldsymbol{x}))}{u_{i j}-g_{i j}}+d_{i j}^{-}-d_{i j}^{+}=1 & i=1,2, \ldots, p, \quad j=1,2, \ldots, m_{i} \\
\frac{x_{i k}-\left(x_{i k}^{*}-t_{k}^{i_{L}}\right)}{t_{k}^{i_{L}}}+d_{i k}^{L-}-d_{i k}^{L+}=1 & i=1,2, \ldots, p-1, k=1,2, \ldots, n_{i} \\
\frac{\left(x_{i k}^{*}+t_{k}^{i^{R}}\right)-x_{i k}}{t_{k}^{i_{R}}}+d_{i k}^{R-}-d_{i k}^{R+}=1 & i=1,2, \ldots, p-1, k=1,2, \ldots, n_{i}
\end{array}
$$


Military Technical College

Kobry Elkobbah,

Cairo, Egypt

May $29-31,2012$ $6^{\text {th }}$ International Conference

on Mathematics and

Engineering Physics

(ICMEP-6)

Where $d_{i k}^{-}=\left(d_{i k}^{L-}, d_{i k}^{R-}\right), d_{i k}^{+}=\left(d_{i k}^{L+}, d_{i k}^{R+}\right)$, and $d_{i j}^{-}, d_{i k}^{L-}, d_{i k}^{R-}, d_{i j}^{+}, d_{i k}^{L+}, d_{i k}^{R+} \geq 0$ with $d_{i j}^{-} \times d_{i j}^{+}=0, \quad d_{i k}^{L-} \times d_{i k}^{L+}=0, \quad$ and $\quad d_{i k}^{R-} \times d_{i k}^{R+}=0, \quad i=1,2, \ldots, p-1, \quad k=1,2, \ldots, n_{i}$, represent the under- and over-deviations, respectively, from the aspired levels.

In conventional GP, the under- and/or over-deviational variables are included in the achievement function for minimizing them and that depend upon the type of the objective functions to be optimized. In this approach, the over-deviational variables for the fuzzy goals of objective functions, $d_{i j}^{+}, i=1,2, \ldots, p, j=1,2, \ldots, m_{i}$, and the overdeviational and the under- deviational variables for the fuzzy goals of the decision variables $, d_{i k}^{L-}, d_{i k}^{L+}, d_{i k}^{R-}$, and $d_{i k}^{R+}, i=1,2, \ldots, p-1, k=1,2, \ldots, n_{i}$, are required to be minimized to achieve the aspired levels of the fuzzy goals. It may be noted that any under-deviation from a fuzzy goal indicates the full achievement of the membership value [20].

It can be easily realized that the membership goals in (5) are inherently nonlinear in nature and this may create computational difficulties in the solution process. To avoid such problems, a linearization procedure is presented in the following section.

\subsection{Linearization of Membership Goals}

Following B.B. Pal et al. [20], the $i j^{\text {th }}$ membership goals in (9) can be presented as:

$$
L_{i j} u_{i j}-L_{i j} f_{i j}(\boldsymbol{x})+d_{i j}^{-}-d_{i j}^{+}=1 \text { where } L_{i j}=\frac{1}{u_{i j}-g_{i j}}
$$

Introducing the expression of $f_{i j}(\boldsymbol{x})$ from (4), the above goal can be presented as:

$$
\begin{aligned}
& L_{i j} u_{i j}-L_{i j} \frac{\boldsymbol{c}_{i j} x+\alpha_{i j}}{\boldsymbol{d}_{i j} x+\beta_{i j}}+d_{i j}^{-}-d_{i j}^{+}=1 \\
\Rightarrow & L_{i j} u_{i j}\left(\boldsymbol{d}_{i j} x+\beta_{i j}\right)-L_{i j}\left(\boldsymbol{c}_{i j} x+\alpha_{i j}\right)+d_{i j}^{-}\left(\boldsymbol{d}_{i j} x+\beta_{i j}\right)-d_{i j}^{+}\left(\boldsymbol{d}_{i j} x+\beta_{i j}\right)=\left(\boldsymbol{d}_{i j} x+\beta_{i j}\right) \\
\Rightarrow & -L_{i j}\left(\boldsymbol{c}_{i j} \boldsymbol{x}+\alpha_{i j}\right)+d_{i j}^{-}\left(\boldsymbol{d}_{i j} \boldsymbol{x}+\beta_{i j}\right)-d_{i j}^{+}\left(\boldsymbol{d}_{i j} \boldsymbol{x}+\beta_{i j}\right)=\left[1-L_{i j} u_{i j}\right]\left(\boldsymbol{d}_{i j} \boldsymbol{x}+\beta_{i j}\right) \\
\Rightarrow & -L_{i j}\left(\boldsymbol{c}_{i j} \boldsymbol{x}+\alpha_{i j}\right)+d_{i j}^{-}\left(\boldsymbol{d}_{i j} \boldsymbol{x}+\beta_{i j}\right)-d_{i j}^{+}\left(\boldsymbol{d}_{i j} \boldsymbol{x}+\beta_{i j}\right)=L_{i j}^{\prime}\left(\boldsymbol{d}_{i j} \boldsymbol{x}+\beta_{i j}\right) \text { where } L_{i j}^{\prime}=1-L_{i j} u_{i j} \\
\Rightarrow & \left(-L_{i j} \boldsymbol{c}_{i j}-L_{i j}^{\prime} \boldsymbol{d}_{i j}\right) \boldsymbol{x}+d_{i j}^{-}\left(\boldsymbol{d}_{i j} \boldsymbol{x}+\beta_{i j}\right)-d_{i j}^{+}\left(\boldsymbol{d}_{i j} \boldsymbol{x}+\beta_{i j}\right)=L_{i j} \alpha_{i j}+L_{i j}^{\prime} \beta_{i j} \\
\Rightarrow & \boldsymbol{C}_{i j} \boldsymbol{x}+d_{i j}^{-}\left(\boldsymbol{d}_{i j} \boldsymbol{x}+\beta_{i j}\right)-d_{i j}^{+}\left(\boldsymbol{d}_{i j} \boldsymbol{x}+\beta_{i j}\right)=\boldsymbol{G}_{i j}
\end{aligned}
$$

where

$$
\boldsymbol{C}_{i j}=-L_{i j} \boldsymbol{c}_{i j}-L_{i j}^{\prime} \boldsymbol{d}_{i j} \text { and } \boldsymbol{G}_{i j}=L_{i j} \alpha_{i j}+L_{i j}^{\prime} \beta_{i j}
$$

Now, using the method of variable change as presented by Kornbluth and Steuer $[12,20,31]$, the goal expression in (14) can be linearized as follows: 
Military Technical College

Kobry Elkobbah,

Cairo, Egypt

May $29-31,2012$ $6^{\text {th }}$ International Conference

on Mathematics and

Engineering Physics

(ICMEP-6)

Let $D_{i j}^{-}=d_{i j}^{-}\left(d_{i j} x+\beta_{i j}\right)$ and $D_{i j}^{+}=d_{i j}^{+}\left(\boldsymbol{d}_{i j} x+\beta_{i j}\right)$, the linear form of the expression in (14) is obtained as:

$$
\boldsymbol{C}_{i j} \boldsymbol{x}+D_{i j}^{-}-D_{i j}^{+}=\boldsymbol{G}_{i j}
$$

with $D_{i j}^{-}, D_{i j}^{+} \geq 0$ and $D_{i j}^{-} \times D_{i j}^{+}=0$ since $d_{i j}^{-}, d_{i j}^{+} \geq 0$ and $\boldsymbol{d}_{i j} x+\beta_{i j}>0$.

Now, in making decision, minimization of $d_{i j}^{+}$means minimization of $D_{i j}^{+}=d_{i j}^{+}\left(\boldsymbol{d}_{i j} x+\beta_{i j}\right)$, which is also a non-linear one.

It may be noted that when a membership goal is fully achieved, $d_{i j}^{+}=0$ and when its achievement is zero, $d_{i j}^{+}=1$ are found in the solution [20]. So, involvement of $d_{i j}^{+} \leq 1$ in the solution leads to impose the following constraint to the model of the problem:

$$
\frac{D_{i j}^{+}}{\boldsymbol{d}_{i j} x+\beta_{i j}} \leq 1 \quad \text { i.e. }-\boldsymbol{d}_{i j} \boldsymbol{x}+D_{i j}^{+} \leq \beta_{i j}
$$

Here, on the basis of the previous discussion, it may be pointed out that any such constraint corresponding to $d_{i j}^{-}$does not arise in the model formulation [20].

\subsection{The FGP model to MOLFP problems}

Following any MOLFP approaches [10,11,12,15,22], the optimal solutions $\boldsymbol{x}^{i^{*}}=\left(\boldsymbol{x}_{1}^{i^{*}}, \boldsymbol{x}_{2}^{i^{*}}, \ldots, \boldsymbol{x}_{p}^{i^{*}}\right), i=1,2, \ldots, p-1$, of the MOLFP problems of the $i^{\text {th }}$-level DM, respectively, could be obtained. The FGP approach of B.B. Pal et al approach [20] that solve single-level MOLFP problems is considered, in this paper, to solve the MOLFP problems of the $i^{\text {th }}$-level DM, $i=1,2, \ldots, p-1$. The FGP model formulation of this approach can be stated as [20]:

$\min Z=\sum_{j=1}^{m_{i}} w_{i j}^{+} D_{i j}^{+}$

subject to

$$
\begin{aligned}
& \boldsymbol{C}_{i j} \boldsymbol{x}+D_{i j}^{-}-D_{i j}^{+}=\boldsymbol{G}_{i j}, j=1,2, \ldots, m_{i} \\
& -\boldsymbol{d}_{i j} \boldsymbol{x}+D_{i j}^{+} \leq \beta_{i j} \quad, j=1,2, \ldots, m_{i}
\end{aligned}
$$


Military Technical College

Kobry Elkobbah,

Cairo, Egypt

May $29-31,2012$ $6^{\text {th }}$ International Conference

on Mathematics and

Engineering Physics

(ICMEP-6)

$$
\begin{aligned}
& \mathrm{A}_{1} x_{1}+\mathrm{A}_{2} x_{2}+\ldots+\mathrm{A}_{p} x_{p}\left(\begin{array}{l}
\leq \\
= \\
\geq
\end{array}\right) \boldsymbol{b}, \boldsymbol{x} \geq 0 \\
& D_{i j}^{-} \times D_{i j}^{+}=0, \text { and } D_{i j}^{-}, D_{i j}^{+} \geq 0, j=1,2, \ldots, m_{i}
\end{aligned}
$$

where $\mathrm{Z}$ represents the fuzzy achievement function and the numerical weights $w_{i j}^{+}, \quad i=1,2, \ldots, p, j=1,2, \ldots, m_{i}$ represent the relative importance of achieving the aspired levels of the respective fuzzy goals subject to the constraints set in the decision situation. To assess the relative importance of the fuzzy goals properly, the weighting scheme suggested by Mohamed [8] can be used to assign the values of $w_{i j}^{+}$, $i=1,2, \ldots, p, j=1,2, \ldots, m_{i}$. In the present formulation, these values are determined as:

$$
w_{i j}^{+}=\frac{1}{u_{i j}-g_{i j}}, \quad i=1,2, \ldots, p, j=1,2, \ldots, m_{i}
$$

\section{FGP Algorithms to TL-MOLFP}

The FGP approach to multiobjective programming problems presented by Mohamed [16] is extended here to formulate two FGP algorithms to multi-level multiobjective linear fractional programming problem.

\subsection{The First FGP Algorithm to TL-MOLFP}

The first FGP procedure proposed in this article, as mentioned in the introduction, groups the membership functions for the defined fuzzy goals of the objective functions at all levels as well as the membership functions of the fuzzy goals of the decision variables, which evaluated separately, of the $p-1$ upper levels problems. Therefore, considering the goal achievement problem of the goals at the same priority level, the equivalent proposed fuzzy multi-level multi-objective linear fractional goal programming model of the problem, under the framework of minsum GP, can be presented as:

$$
\begin{aligned}
\min Z & =\sum_{j=1}^{m_{1}} w_{1 j}^{+} d_{1 j}^{+}+\sum_{j=1}^{m_{2}} w_{2 j}^{+} d_{2 j}^{+}+\ldots+\sum_{j=1}^{m_{p}} w_{p j}^{+} d_{p j}^{+} \\
& +\sum_{k=1}^{n_{1}}\left[w_{1 k}^{L}\left(d_{1 k}^{L-}+d_{1 k}^{L+}\right)+w_{1 k}^{R}\left(d_{1 k}^{R-}+d_{1 k}^{R+}\right)\right] \\
& +\sum_{k=1}^{n_{2}}\left[w_{2 k}^{L}\left(d_{2 k}^{L-}+d_{2 k}^{L+}\right)+w_{2 k}^{R}\left(d_{2 k}^{R-}+d_{2 k}^{R+}\right)\right]
\end{aligned}
$$


Military Technical College

Kobry Elkobbah,

Cairo, Egypt

May $29-31,2012$ $6^{\text {th }}$ International Conference on Mathematics and Engineering Physics

(ICMEP-6)

subject to

$$
+\sum_{k=1}^{n_{p-1}}\left[w_{p-1 k}^{L}\left(d_{p-1 k}^{L-}+d_{p-1 k}^{L+}\right)+w_{p-1 k}^{R}\left(d_{p-1 k}^{R-}+d_{p-1 k}^{R+}\right)\right]
$$

$$
\begin{aligned}
& \mu_{f_{1 j}}\left(f_{1 j}(\boldsymbol{x})\right)+d_{1 j}^{-}-d_{2 j}^{+}=1 \quad, j=1,2, \ldots, m_{1} \\
& \mu_{f_{2 j}}\left(f_{2 j}(\boldsymbol{x})\right)+d_{2 j}^{-}-d_{2 j}^{+}=1 \quad, j=1,2, \ldots, m_{2} \\
& \mu_{f_{p j}}\left(f_{j}(\boldsymbol{x})\right)+d_{p j}^{-}-d_{p j}^{+}=1 \quad, j=1,2, \ldots, m_{p} \\
& \mu_{x_{1 k}}\left(x_{1 k}\right)+d_{1 k}^{-}-d_{1 k}^{+}=1 \quad, k=1,2, \ldots, n_{1} \\
& \mu_{x_{2 k}}\left(x_{2 k}\right)+d_{2 k}^{-}-d_{2 k}^{+}=1 \quad, k=1,2, \ldots, n_{2} \\
& \mu_{x_{p-1 k}}\left(x_{p-1 k}\right)+d_{p-1 k}^{-}-d_{p-1 k}^{+}=1, k=1,2, \ldots, n_{p-1} \\
& \mathrm{~A}_{1} x_{1}+\mathrm{A}_{2} x_{2}+\ldots+\mathrm{A}_{p} x_{p}\left(\begin{array}{l}
\leq \\
= \\
\geq
\end{array}\right) \boldsymbol{b}, \boldsymbol{x} \geq 0 \\
& d_{i j}^{-}, d_{i j}^{+} \geq 0 \text { and } d_{i j}^{-} \times d_{i j}^{+}=0, i=1,2, \ldots, p, \quad j=1,2, \ldots, m_{i} \\
& d_{i k}^{-}, d_{i k}^{+} \geq 0 \text { and } d_{i k}^{-} \times d_{i k}^{+}=0, \quad i=1,2, \ldots, p-1, \quad k=1,2, \ldots, n_{i}
\end{aligned}
$$

the above problem can be rewritten as:

$$
\begin{aligned}
\min Z & =\sum_{j=1}^{m_{1}} w_{1 j}^{+} d_{1 j}^{+}+\sum_{j=1}^{m_{2}} w_{2 j}^{+} d_{2 j}^{+}+\ldots+\sum_{j=1}^{m_{p}} w_{p j}^{+} d_{p j}^{+} \\
& +\sum_{k=1}^{n_{1}}\left[w_{1 k}^{L}\left(d_{1 k}^{L-}+d_{1 k}^{L+}\right)+w_{1 k}^{R}\left(d_{1 k}^{R-}+d_{1 k}^{R+}\right)\right] \\
& +\sum_{k=1}^{n_{2}}\left[w_{2 k}^{L}\left(d_{2 k}^{L-}+d_{2 k}^{L+}\right)+w_{2 k}^{R}\left(d_{2 k}^{R-}+d_{2 k}^{R+}\right)\right] \\
& \vdots \\
& +\sum_{k=1}^{n_{p-1}}\left[w_{p-1 k}^{L}\left(d_{p-1 k}^{L-}+d_{p-1 k}^{L+}\right)+w_{p-1 k}^{R}\left(d_{p-1 k}^{R-}+d_{p-1 k}^{R+}\right)\right]
\end{aligned}
$$

subject to

$$
\frac{u_{i j}-f_{i j}(\boldsymbol{x})}{u_{i j}-g_{i j}}+d_{i j}^{-}-d_{i j}^{+}=1, \quad i=1,2, \ldots, p, \quad j=1,2, \ldots, m_{i}
$$


Military Technical College

Kobry Elkobbah,

Cairo, Egypt

May $29-31,2012$ $6^{\text {th }}$ International Conference on Mathematics and Engineering Physics

(ICMEP-6)

$$
\begin{aligned}
& \frac{x_{i k}-\left(x_{i k}^{*}-t_{k}^{i_{L}}\right)}{t_{k}^{i_{L}}}+d_{i k}^{L-}-d_{i k}^{L+}=1, \quad i=1,2, \ldots, p-1, \quad k=1,2, \ldots, n_{i} \\
& \frac{\left(x_{i k}^{*}+t_{k}^{i_{R}}\right)-x_{i k}}{t_{k}^{i_{R}}}+d_{i k}^{R-}-d_{i k}^{R+}=1, \quad i=1,2, \ldots, p-1, k=1,2, \ldots, n_{i} \\
& \mathrm{~A}_{1} x_{1}+\mathrm{A}_{2} x_{2}+\ldots+\mathrm{A}_{p} x_{p}\left(\begin{array}{l}
\leq \\
= \\
\geq
\end{array}\right) \boldsymbol{b}, \quad x \geq 0 \\
& d_{i j}^{-}, d_{i j}^{+} \geq 0 \text { and } d_{i j}^{-} \times d_{i j}^{+}=0, \quad i=1,2, \ldots, p, \quad j=1,2, \ldots, m_{i} \\
& d_{i k}^{L-}, d_{i k}^{L+} \geq 0 \text { and } d_{i k}^{L-} \times d_{i k}^{L+}=0, i=1,2, \ldots, p-1, \quad k=1,2, \ldots, n_{i} \\
& d_{i k}^{R-}, d_{i k}^{R+} \geq 0 \text { and } d_{i k}^{R-} \times d_{i k}^{R+}=0, i=1,2, \ldots, p-1, \quad k=1,2, \ldots, n_{i}
\end{aligned}
$$

Following the above discussion and linearization process, the equivalent FGP model of problem (17), becomes:

$$
\begin{aligned}
\min Z & =\sum_{j=1}^{m_{1}} w_{1 j}^{+} D_{1 j}^{+}+\sum_{j=1}^{m_{2}} w_{2 j}^{+} D_{2 j}^{+}+\ldots+\sum_{j=1}^{m_{p}} w_{p j}^{+} D_{p j}^{+} \\
& +\sum_{k=1}^{n_{1}}\left[w_{1 k}^{L}\left(d_{1 k}^{L-}+d_{1 k}^{L+}\right)+w_{1 k}^{R}\left(d_{1 k}^{R-}+d_{1 k}^{R+}\right)\right] \\
& +\sum_{k=1}^{n_{2}}\left[w_{2 k}^{L}\left(d_{2 k}^{L-}+d_{2 k}^{L+}\right)+w_{2 k}^{R}\left(d_{2 k}^{R-}+d_{2 k}^{R+}\right)\right] \\
& \vdots \\
& +\sum_{k=1}^{n_{p-1}}\left[w_{p-1 k}^{L}\left(d_{p-1 k}^{L-}+d_{p-1 k}^{L+}\right)+w_{p-1 k}^{R}\left(d_{p-1 k}^{R-}+d_{p-1 k}^{R+}\right)\right]
\end{aligned}
$$

subject to

$$
\begin{array}{ll}
\boldsymbol{C}_{i j} \boldsymbol{x}+D_{i j}^{-}-D_{i j}^{+}=\boldsymbol{G}_{i j}, & i=1,2, \ldots, p, \quad j=1,2, \ldots, m_{i} \\
\frac{x_{i k}-\left(x_{i k}^{*}-t_{k}^{i_{L}}\right)}{t_{k}^{i_{L}}}+d_{i k}^{L-}-d_{i k}^{L+}=1, & i=1,2, \ldots, p-1, \quad k=1,2, \ldots, n_{i} \\
\frac{\left(x_{i k}^{*}+t_{k}^{i_{R}}\right)-x_{i k}}{t_{k}^{i_{R}}}+d_{i k}^{R-}-d_{i k}^{R+}=1, & i=1,2, \ldots, p-1, \quad k=1,2, \ldots, n_{i} \\
-\boldsymbol{d}_{i j} \boldsymbol{x}+D_{i j}^{+} \leq \beta_{i j}, & i=1,2, \ldots, p, \quad j=1,2, \ldots, m_{i} \\
\mathrm{~A}_{1} x_{1}+\mathrm{A}_{2} x_{2}+\ldots+\mathrm{A}_{p} x_{p}\left(\begin{array}{l}
\leq \\
= \\
\geq
\end{array}\right) \boldsymbol{b}, \boldsymbol{x} \geq 0
\end{array}
$$


Military Technical College

Kobry Elkobbah,

Cairo, Egypt

May $29-31,2012$ $6^{\text {th }}$ International Conference

on Mathematics and

Engineering Physics

(ICMEP-6)

$$
\begin{aligned}
& D_{i j}^{-}, D_{i j}^{+} \geq 0 \text { and } D_{i j}^{-} \times D_{i j}^{+}=0, \quad i=1,2, \ldots, p, \quad j=1,2, \ldots, m_{i} \\
& d_{i k}^{L-}, d_{i k}^{L+} \geq 0 \text { and } d_{i k}^{L-} \times d_{i k}^{L+}=0, \quad i=1,2, \ldots, p-1, \quad k=1,2, \ldots, n_{i} \\
& d_{i k}^{R-}, d_{i k}^{R+} \geq 0 \text { and } d_{i k}^{R-} \times d_{i k}^{R+}=0, \quad i=1,2, \ldots, p-1, \quad k=1,2, \ldots, n_{i}
\end{aligned}
$$

Where $\mathrm{Z}$ represents the fuzzy achievement function consisting of the weighted over-deviational variables $D_{i j}^{+}, i=1,2, \ldots, p, j=1,2, \ldots, m_{i}$ of the fuzzy goals $g_{i j}$ and the under-deviational and the over-deviational variables $d_{i k}^{R-}, d_{i k}^{R+}, d_{i k}^{L-}$, and $d_{i k}^{L+}$, $i=1,2, \ldots, p-1, \quad k=1,2, \ldots, n_{i}$ for the fuzzy goals of all the decision variables for the upper $p-1$ levels, where the numerical weights $w_{i j}^{+}, w_{i k}^{R}$, and $w_{i k}^{L}$ represent the relative importance of achieving the aspired levels of the respective fuzzy goals subject to the constraints set in the decision situation.

Again, to assess the relative importance of the fuzzy goals properly, the weighting scheme suggested by Mohamed [16] can be used to assign the values of $w_{i k}^{R}$, and $w_{i k}^{L}$. In the present formulation, these values are determined as:

$$
w_{i k}^{L}=\frac{1}{t_{k}^{i_{L}}} \quad \text { and } \quad w_{i k}^{R}=\frac{1}{t_{k}^{i_{R}}}, \quad i=1,2, \ldots, p-1, k=1,2, \ldots, n_{i}
$$

The FGP model (18) provides the most satisfactory decision for all the DMs at all levels by achieving the aspired levels of the membership goals to the extent possible in the decision environment. The solution procedure is straightforward and illustrated via the illustrative example in section 5 .

\section{FGP Alg. I:}

Following the above discussion, we can now construct the first proposed FGP algorithm for solving ML-MOLFP problems:

Step 1. Calculate the individual minimum and maximum values of all the objective functions for all levels under the given constraints

Step 2. Set the goals and the upper tolerance limits - $u_{i j}, g_{i j}, i=1,2, \ldots, p$, $j=1,2, \ldots, m_{i}$ - for all the objective functions in all levels.

Step 3. Evaluate the weights $w_{i j}^{+}=\frac{1}{u_{i j}-g_{i j}}, \quad i=1,2, \ldots, p-1, j=1,2, \ldots, m_{i}$

Step 4. Set $\mathbf{l}=1$

Step 5. Elicit the membership functions $\mu_{f_{1 j}}\left(f_{1 j}(\boldsymbol{x})\right), j=1,2, \ldots, m_{1}$

Step 6. Formulate the Model (15) for the $\mathbf{I}^{\text {th }}$-level MOLFP problem 
Military Technical College

Kobry Elkobbah,

Cairo, Egypt

May $29-31,2012$ $6^{\text {th }}$ International Conference on Mathematics and Engineering Physics

(ICMEP-6)

Step 7. Solve the Model (15) to get $\boldsymbol{x}^{1^{*}}=\left(\boldsymbol{x}_{1}^{1^{*}}, \boldsymbol{x}_{2}^{1^{*^{*}}}, \ldots, \boldsymbol{x}_{p}^{1^{*}}\right)$.

Step 8. Set the maximum negative and positive tolerance values on the decision vector $\boldsymbol{x}_{\mathbf{1}}^{\mathbf{1}^{*}}=\left(x_{11}^{*}, x_{12}^{*}, \ldots, x_{1 n_{1}}^{*}\right), t_{k}^{1}{ }^{1}$ and $t_{k}^{1}{ }_{R}, k=1,2, \ldots, n_{1}$.

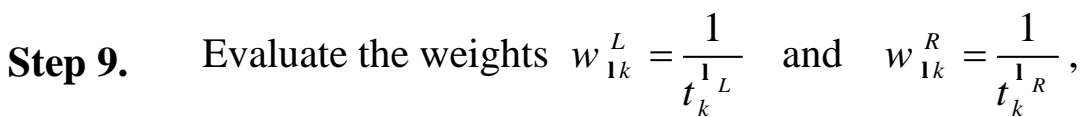

Step 10. Elicit the membership functions $\mu_{x_{1 k}}\left(x_{1 k}\right), k=1,2, \ldots, n_{1}$ for decision vector $\boldsymbol{x}_{\mathbf{1}}^{1^{*}}=\left(x_{11}^{*}, x_{12}^{*}, \ldots, x_{1 n_{1}}^{*}\right)$, equation (6).

Step 11. $\mathbf{I}=\mathbf{l}+1$, if $\mathbf{l}>p-1$, then go to Step 12 , else go to Step 5 .

Step 12. Elicit the membership functions $\mu_{f_{p j}}\left(f_{p j}(\boldsymbol{x})\right), j=1,2, \ldots, m_{p}$ for the objective functions in the $p^{\text {th }}-$ level.

Step 13. Evaluate the weights $w_{p j}^{+}=\frac{1}{u_{p j}-g_{p j}}, \quad j=1,2, \ldots, m_{p}$

Step 14. Formulate the Model (18) for the ML-MOLFP problem

Step 15. Solve the Model (18) to get the satisfactory solution of the ML-MOLFP problem

\subsection{The Second FGP Algorithm to TL-MOLFP}

In Alg I, the final model contains the membership functions for the fuzzy goals of the decision variables controlled by p-1 upper levels, that separately solved for the MOLFP problem of the $\mathrm{p}^{\text {th }}$ level DM. The second proposed algorithm, lexicographically solve MOLFP problems of the ML-MOLFP problem that take into consideration, the decisions of the MOLFP problems for the upper levels. As mentioned in the introduction, after the initialization steps - step 1 to step 3 in Alg I - the solution procedure starts with the MOLFP problem of the FLDM obtaining the satisfactory solution. A relaxation of the FLDM decisions is considered to avoid decision deadlock. This decisions of the FLDM are modeled by membership functions of fuzzy set theory and passed to the SLDM as additional constrains. Then, the SLDM take into consideration the membership goals of the objectives and decision variables of the FLDM. Thereafter, the attained solution is sent to the TLDM who seeks the solution in a similar manner. The process is repeated until the lower level is reached. Following this discussion, we now in place to introduce the second proposed FGP algorithm for solving ML-MOLFP problems:

\section{FGP Alg. II:}

Step 1. Calculate the individual minimum and maximum values of all the objective functions for all levels under the given constraints

Step 2. Set the goals and the upper tolerance limits $-u_{i j}, g_{i j}, i=1,2, \ldots, p$, 
Military Technical College

Kobry Elkobbah,

Cairo, Egypt

May $29-31,2012$ $6^{\text {th }}$ International Conference

on Mathematics and

Engineering Physics

(ICMEP-6)

$j=1,2, \ldots, m_{i}$ - for all the objective functions in all levels.

Step 3. Evaluate the weights $w_{i j}^{+}=\frac{1}{u_{i j}-g_{i j}}, \quad i=1,2, \ldots, p-1, j=1,2, \ldots, m_{i}$

Step 4. Set $\mathbf{l}=1$

Step 5. Elicit the membership functions $\mu_{f_{1 j}}\left(f_{1 j}(\boldsymbol{x})\right), j=1,2, \ldots, m_{1}$

Step 6. Formulate the Model (15) for the $\mathbf{I}^{\text {th }}$-level MOLFP problem

Step 7. Solve the Model (15) to get $\boldsymbol{x}^{1^{*}}=\left(\boldsymbol{x}_{1}^{1^{*}}, \boldsymbol{x}_{2}^{1^{*}}, \ldots, \boldsymbol{x}_{p}^{1^{*}}\right)$.

Step 8. Set the maximum negative and positive tolerance values on the decision vector $\boldsymbol{x}_{1}^{1^{*}}=\left(x_{11}^{*}, x_{12}^{*}, \ldots, x_{1_{n_{1}}}^{*}\right), t_{k}^{1_{L}}$ and $t_{k}^{1_{R}}, k=1,2, \ldots, n_{\mathbf{1}}$.

Step 9. Evaluate the weights $w_{1 k}^{L}=\frac{1}{t_{k}^{1_{L}}}$ and $w_{1 k}^{R}=\frac{1}{t_{k}^{1_{R}}}$,

Step 10. Elicit the membership functions $\mu_{x_{1 k}}\left(x_{1 k}\right), k=1,2, \ldots, n_{1}$ for decision vector $\boldsymbol{x}_{1}^{1^{*}}=\left(x_{11}^{*}, x_{12}^{*}, \ldots, x_{1 n_{1}}^{*}\right)$.

Step 11. Formulate the Model (18) for the ML-MOLFP problem with $p=\mathbf{l}$

Step 12. Solve the Model (18) to get the solution $\boldsymbol{x}^{1^{*}}=\left(\boldsymbol{x}_{1}^{1^{*}}, \boldsymbol{x}_{2}^{1^{*}}, \ldots, \boldsymbol{x}_{p}^{1^{*}}\right)$

Step $13 \quad \mathbf{l}=\mathbf{l}+1$

Step 14 if $\mathbf{l}>p$, then stop with the satisfactory solution $\boldsymbol{x}^{1^{*}}=\left(\boldsymbol{x}_{1}^{1^{*}}, \boldsymbol{x}_{2}^{1^{*}}, \ldots, \boldsymbol{x}_{p}^{1^{*}}\right)$

to the ML-MOLFP problem, else go to Step 8.

\section{Numerical Example}

To demonstrate proposed FGP procedures, consider the following Three level multiobjective linear fractional programming problem:

$\left[1^{\text {st }}\right.$ Level $] \quad \operatorname{Min}_{x_{1}}\left(f_{11}=\frac{3 x_{1}-2 x_{2}+2 x_{3}}{x_{1}+x_{2}+x_{3}+3}, f_{12}=\frac{-7 x_{1}-2 x_{2}+x_{3}+1}{5 x_{1}+2 x_{2}+x_{3}+1}\right)$

where $x_{2}$ and $x_{3}$ solve

$\left[2^{\text {nd }}\right.$ Level $] \quad \operatorname{Min}_{x_{2}}\left(f_{21}=\frac{-x_{1}-4 x_{2}+x_{3}+1}{2 x_{1}+3 x_{2}+x_{3}+2}, f_{22}=\frac{-2 x_{1}+x_{2}+3 x_{3}+4}{2 x_{1}-x_{2}+x_{3}+5}\right)$

where $x_{3}$ solves

$\left[3^{\text {rd }}\right.$ Level $] \quad \operatorname{Min}_{x_{3}}\left(f_{31}=\frac{x_{1}+x_{2}+x_{3}-4}{x_{1}-2 x_{2}+10 x_{3}+6}, f_{32}=\frac{2 x_{1}-x_{2}+x_{3}+4}{-x_{1}+x_{2}+x_{3}+10}\right)$

subject to

$$
x_{1}+x_{2}+x_{3} \leq 5 \quad-x_{1}+x_{2}+x_{3} \leq 1
$$


Military Technical College

Kobry Elkobbah,

Cairo, Egypt

May $29-31,2012$ $6^{\text {th }}$ International Conference

on Mathematics and

Engineering Physics

(ICMEP-6)

$$
\begin{array}{ll}
x_{1}+x_{2}-x_{3} \leq 2 & x_{1}-x_{2}+x_{3} \leq 4 \\
x_{1}+x_{2}+x_{3} \geq 1 & x_{1} \quad+2 x_{3} \leq 4 \\
x_{1}, x_{2}, x_{3} \geq 0 . &
\end{array}
$$

Table (1) summarizes the coefficients $\alpha_{i j}, \beta_{i j}, \boldsymbol{c}_{i j}$, and $\boldsymbol{d}_{i j}$ for all the three levels objectives of the ML-MOLFP problem. Also, the optimal minimum and maximum separate solutions of these objectives subjected to given constraints. The decided aspiration levels and upper tolerance limits to the objective functions are also mentioned. The values $L_{\mathrm{ij}}, L_{i j}^{\prime}, \boldsymbol{C}_{i j}$, $\boldsymbol{G}_{i j}$, and the weights $w_{\mathrm{ij}}$ are calculated and also contained in the table.

The first Algorithm, Alg I, can be explained through the solution procedure of the second Algorithm, Alg II. Then, following Alg II, the proposed FGP procedure to the multi-level multiobjective linear fractional programming problem proceeds as:

First Level DM FGP model:

$\min Z=0.56 D_{11}^{+}+0.5 D_{12}^{+}$

subject to

$$
\begin{gathered}
-1.96 x_{1}+0.84 x_{2}-1.4 x_{3}+D_{11}^{-}-D_{11}^{+}=0.834 \\
x_{1} \quad-x_{3}+D_{12}^{-}-D_{12}^{+}=1 \\
-x_{1}-x_{2}-x_{3}+D_{11}^{+} \leq 3 \\
-5 x_{1}-2 x_{2}-x_{3}+D_{12}^{+} \leq 1 \\
x_{1}+x_{2}+x_{3} \leq 5 \quad-x_{1}+x_{2}+x_{3} \leq 1 \\
x_{1}+x_{2}-x_{3} \leq 2 \\
x_{1}+x_{2}+x_{3} \geq 1 \quad x_{1}-x_{2}+x_{3} \leq 4 \\
x_{1}, x_{2}, x_{3} \geq 0 . \\
D_{i j}^{-}, D_{i j}^{+} \geq 0 \text { and } \quad D_{i j}^{-} \times D_{i j}^{+}=0, i=1 j=1,2,
\end{gathered}
$$

\begin{tabular}{|l|l|l|l|l|l|l|}
\cline { 2 - 7 } \multicolumn{1}{c|}{} & \multicolumn{1}{c|}{$f_{11}$} & \multicolumn{1}{c|}{$f_{12}$} & \multicolumn{1}{c|}{$f_{21}$} & \multicolumn{1}{c|}{$f_{22}$} & \multicolumn{1}{c|}{$f_{31}$} & \multicolumn{1}{c|}{$f_{32}$} \\
\hline$\alpha_{i j}$ & 0 & 1 & 1 & 4 & -4 & 4 \\
\hline$\beta_{i j}$ & 3 & 1 & 2 & 5 & 6 & 10 \\
\hline $\boldsymbol{c}_{i j}$ & $(3,-2,2)$ & $(-7,-2,1)$ & $(-1,-4,1)$ & $(-2,1,3)$ & $(1,1,1)$ & $(2,-1,1)$ \\
\hline $\boldsymbol{d}_{i j}$ & $(1,1,1)$ & $(5,2,1)$ & $(2,3,1)$ & $(2,-1,1)$ & $(1,-2,10)$ & $(-1,1,1)$ \\
\hline $\min _{G} f_{i j}$ & -0.5 & -1.18 & -0.733 & 0 & -0.75 & 0.2727 \\
\hline $\max _{G} f_{\mathrm{ij}}$ & 1.353 & 1 & 0.667 & 1.25 & -0.026 & 1.125 \\
\hline
\end{tabular}


Military Technical College

Kobry Elkobbah,

Cairo, Egypt

May $29-31,2012$ $6^{\text {th }}$ International Conference on Mathematics and Engineering Physics

(ICMEP-6)

\begin{tabular}{|l|l|l|l|l|l|l|}
\hline$g_{\mathrm{ij}}$ & -0.5 & -1 & -0.7 & 0 & -0.75 & 0.25 \\
\hline$u_{\mathrm{ij}}$ & 1.3 & 1 & 0.6 & 1.2 & -0.05 & 1.125 \\
\hline$L_{\mathrm{ij}}$ & 0.56 & 0.5 & 0.769 & 0.83 & 1.43 & 1.143 \\
\hline$L_{i j}^{\prime}$ & 0.278 & 0.5 & 0.54 & 0.004 & 0.93 & -0.29 \\
\hline $\boldsymbol{C}_{i j}$ & $(-1.96,0.84,-1.4)$ & $(1,0,-1)$ & $(-0.31,1.46,-1.3)$ & $(1.65,-0.83,-2.5)$ & $(-2.36,0.43,-10.7)$ & $(-2.58,1.43,-0.85)$ \\
\hline $\boldsymbol{G}_{i j}$ & 0.834 & 1 & 1.85 & 3.34 & -0.14 & 1.67 \\
\hline$w_{\mathrm{ij}}$ & 0.56 & 0.5 & 0.769 & 0.83 & 1.43 & 1.143 \\
\hline
\end{tabular}

Table 1

Using the LP-ILP linear and integer programming software program, version 1 for windows, the optimal solution of this problem is $\boldsymbol{x}^{1^{*}}=\left(\boldsymbol{x}_{1}^{1^{*}}, \boldsymbol{x}_{2}^{1^{*}}, \boldsymbol{x}_{3}^{1^{*}}\right)=(1,0,0)$. Let the first level DM decide $\boldsymbol{x}_{1}^{1^{*}}=1$ with the negative and positive tolerances $t_{1}^{{ }^{L} L}=t_{1}{ }^{{ }_{R}}=0.5$ with weights $w_{11}^{L}=w_{11}^{R}=\frac{1}{0.5}=2$.

$\underline{\text { Second Level DM FGP model: }}$

$\min Z=0.56 D_{11}^{+}+0.5 D_{12}^{+}+0.769 D_{21}^{+}+0.83 D_{22}^{+}+2\left[\left(d_{11}^{L-}+d_{11}^{L+}\right)+\left(d_{11}^{R-}+d_{11}^{R+}\right)\right]$ subject to

$$
\begin{array}{lc}
-1.96 x_{1}+0.84 x_{2}-1.4 x_{3}+D_{11}^{-}-D_{11}^{+}=0.834 & -x_{3}+D_{12}^{-}-D_{12}^{+}=1 \\
x_{1} & -5 x_{1}-2 x_{2}-x_{3}+D_{12}^{+} \leq 1 \\
-0.31 x_{1}+1.46 x_{2}-1.3 x_{3}+D_{21}^{-}-D_{21}^{+}=1.85 \\
1.65 x_{1}-0.83 x_{2}-2.5 x_{3}+D_{22}^{-}-D_{22}^{+}=3.34 \\
-x_{1}-x_{2}-x_{3}+D_{11}^{+} \leq 3 & -2 x_{1}+x_{2}-x_{3}+D_{22}^{+} \leq 5 \\
-2 x_{1}-3 x_{2}-x_{3}+D_{21}^{+} \leq 2 & -2 x_{1}+d_{11}^{R-}-d_{11}^{R+}=-2 \\
2 x_{1}+d_{11}^{L-}-d_{11}^{L+}=2 & -x_{1}+x_{2}+x_{3} \leq 1 \\
x_{1}+x_{2}+x_{3} \leq 5 & x_{1}-x_{2}+x_{3} \leq 4 \\
x_{1}+x_{2}-x_{3} \leq 2 & +2 x_{3} \leq 4 \\
x_{1}+x_{2}+x_{3} \geq 1 & x_{1} \\
x_{1}, x_{2}, x_{3} \geq 0 . & \\
D_{i j}^{-}, D_{i j}^{+} \geq 0 \text { and } D_{i j}^{-} \times D_{i j}^{+}=0, i=1,2, j=1,2, \\
d_{11}^{L-}, d_{11}^{L+}, d_{11}^{R-}, d_{11}^{R+} \geq 0, d_{11}^{L-} \times d_{11}^{L+}=0, d_{11}^{R-} \times d_{11}^{R+}=0 .
\end{array}
$$


Military Technical College

Kobry Elkobbah,

Cairo, Egypt

May $29-31,2012$ $6^{\text {th }}$ International Conference

on Mathematics and

Engineering Physics

(ICMEP-6)

The optimal solution of this problem is $\boldsymbol{x}^{2^{*}}=\left(\boldsymbol{x}_{1}^{2^{*}}, \boldsymbol{x}_{2}^{2^{*}}, \boldsymbol{x}_{3}^{2^{*}}\right)=(1,1,0)$. Let the second level DM decide $\boldsymbol{x}_{1}^{2^{*}}=1$ with the negative and positive tolerances $t_{1}^{{ }^{2} L}=t_{1}^{2}{ }_{R}=0.5$ with weights $w_{21}^{L}=w_{21}^{R}=\frac{1}{0.5}=2$.

Third Level DM - and the final FGP model to the three-level MOLFP problem- FGP model:

$$
\begin{aligned}
& \min Z=0.56 D_{11}^{+}+0.5 D_{12}^{+}+0.769 D_{21}^{+}+0.83 D_{22}^{+}+1.43 D_{31}^{+}+1.143 D_{32}^{+}+ \\
& 2\left[\left(d_{11}^{L-}+d_{11}^{L+}\right)+\left(d_{11}^{R-}+d_{11}^{R+}\right)\right]+2\left[\left(d_{21}^{L-}+d_{21}^{L+}\right)+\left(d_{21}^{R-}+d_{21}^{R+}\right)\right] \\
& \text { subject to } \\
& -1.96 x_{1}+0.84 x_{2}-1.4 x_{3}+D_{11}^{-}-D_{11}^{+}=0.834 \\
& x_{1} \quad-x_{3}+D_{12}^{-}-D_{12}^{+}=1 \\
& -0.31 x_{1}+1.46 x_{2}-1.3 x_{3}+D_{21}^{-}-D_{21}^{+}=1.85 \\
& 1.65 x_{1}-0.83 x_{2}-2.5 x_{3}+D_{22}^{-}-D_{22}^{+}=3.34 \\
& -2.36 x_{1}+0.43 x_{2}-10.7 x_{3}+D_{31}^{-}-D_{31}^{+}=-0.14 \\
& -2.58 x_{1}+1.43 x_{2}-0.85 x_{3}+D_{11}^{-}-D_{11}^{+}=1.67 \\
& -x_{1}-x_{2}-x_{3}+D_{11}^{+} \leq 3 \quad-5 x_{1}-2 x_{2}-x_{3}+D_{12}^{+} \leq 1 \\
& -2 x_{1}-3 x_{2}-x_{3}+D_{21}^{+} \leq 2 \quad-2 x_{1}+x_{2}-x_{3}+D_{22}^{+} \leq 5 \\
& -x_{1}+2 x_{2}-10 x_{3}+D_{31}^{+} \leq 6 \quad x_{1}-x_{2}-x_{3}+D_{32}^{+} \leq 10 \\
& 2 x_{1}+d_{11}^{L-}-d_{11}^{L+}=2 \quad-2 x_{1}+d_{11}^{R-}-d_{11}^{R+}=-2 \\
& 2 x_{2}+d_{21}^{L-}+d_{21}^{L+}=2 \quad-2 x_{2}+d_{21}^{R-}+d_{21}^{R+}=-2 \\
& x_{1}+x_{2}+x_{3} \leq 5 \quad-x_{1}+x_{2}+x_{3} \leq 1 \\
& x_{1}+x_{2}-x_{3} \leq 2 \quad x_{1}-x_{2}+x_{3} \leq 4 \\
& x_{1}+x_{2}+x_{3} \geq 1 \quad x_{1}+2 x_{3} \leq 4 \\
& x_{1}, x_{2}, x_{3} \geq 0 \text {. } \\
& D_{i j}^{-}, D_{i j}^{+} \geq 0 \text { and } D_{i j}^{-} \times D_{i j}^{+}=0, i=1,2,3, j=1,2 \text {, } \\
& d_{11}^{L-}, d_{11}^{L+}, d_{11}^{R-}, d_{11}^{R+} \geq 0, d_{11}^{L-} \times d_{11}^{L+}=0, d_{11}^{R-} \times d_{11}^{R+}=0 \text {. } \\
& d_{21}^{L-}, d_{21}^{L+}, d_{21}^{R-}, d_{21}^{R+} \geq 0, d_{21}^{R-} \times d_{21}^{R+}=0, d_{21}^{L-} \times d_{21}^{L+}=0 \text {. }
\end{aligned}
$$

The satisfactory solution of the ML-MOLFP problem is $\boldsymbol{x}^{3^{*}}=\left(\boldsymbol{x}_{1}^{3^{*}}, \boldsymbol{x}_{2}^{3^{*}}, \boldsymbol{x}_{3}^{3^{*}}\right)=(1,1,0)$ with objective functions values $f_{11}=0.2, f_{12}=-1$, $f_{21}=-0.57, f_{22}=0.5, f_{31}=-0.4$, and $f_{32}=0.5$, and with membership functions values $\mu_{11}=0.61, \mu_{21}=1, \mu_{21}=0.9, \mu_{22}=0.58, \mu_{31}=0.5$, and $\mu_{32}=0.7$, respectively . 
Military Technical College

Kobry Elkobbah,

Cairo, Egypt

May $29-31,2012$

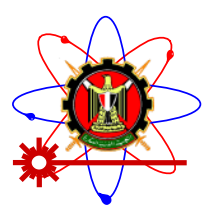

$6^{\text {th }}$ International Conference

on Mathematics and

Engineering Physics

(ICMEP-6)

\section{Conclusion}

This paper presents two fuzzy goal programming procedures for solving multilevel multi-objective linear fractional programming (ML-MOLFP) problems. A fuzzy goal programming model to minimize the group regret of degree of satisfactions of all the decision makers is developed to achieve the highest degree (unity) of each of the defined membership function goals to the extent possible by minimizing their deviational variables and thereby obtaining the most satisfactory solution for all the decision makers. The main advantage of the proposed fuzzy goal programming algorithms is that the possibility of rejecting the solution again and again by the upper decision makers and re-evaluation of the problem repeatedly, by redefining the elicited membership functions, needed to reach the satisfactory decision does not arise.

The first proposed algorithm groups the membership functions for the defined fuzzy goals of the objective functions at all levels as well as the membership functions of the fuzzy goals of the decision variables for each level except the lower level of the multi-level problem. The second proposed algorithm, lexicographically solve MOLFP problems of the ML-MOLFP problem take into consideration, the decisions of the MOLFP problems for the upper levels. A linearization process of solving ML-MOLFP problems via minsum FGP is investigated. An illustrative numerical example is given to demonstrate the algorithms.

\section{References}

[1] M. A. Abo-Sinna and I. A. Baky, Interactive Balance Space Approach for Solving Bi-level MultiObjective Programming Problems, AMSE-Modeling journal, FRANCE (40) (2006) 43-62 Advances B.

[2] M. A. Abo-Sinna and .I A. Baky, Interactive Balance Space Approach for Solving Multi-Level MultiObjective Programming Problems, Information Sciences, Information Sciences 177 (2007) 33973410.

[3] M. A. Abo-Sinna and I. A. Baky, A Comparison of Two Bi-Level programming Methods in MultiObjective Programming Problems Applied To the Supply-Demand Interactions in Electronic Commerce, Scientific Bulletin, Ain Shams University, Faculty of Engineering 40 (4) (2005) pp. 11891213.

[4] M. A. Abo-Sinna, A Bi-level Non-Linear Multi-objective Decision Making Under Fuzziness, Journal of Operational Research Society of India (OPSEARCH) 38 (5) (2001) 484-495.

[5] M. A. Abo-Sinna, Pareto Optimality for Bi-level Programming Problem with Fuzzy parameters, Journal of Operational Research Society of India (OPSEARCH) 38 (4) (2001) 372-393.

[6] G. Anandalingam, A mathematical Programming Model of the Decentralized Multi-Level Systems, Journal of Operations Research Society 39 (11) (1988) 1021-1033.

[7] B. Ayed, Bi-Level Linear programming, Computers and Operations Research 20 (5) (1993) 485-501.

[8] R.E. Bellman and L.A Zadeh, Decision-making in a fuzzy environment, Management Science 17 (1970) 141-164.

[9] W. F. Bialas and M. H. Karwan, Two Level Linear programming, Management Science 30 (8) (1984) 1004-1020.

[10] D. Dutta, R.N. Tiwari, J.R. Rao, Multiple objective linear fractional programming-a fuzzy set 
Military Technical College

Kobry Elkobbah, Cairo, Egypt May 29-31,2012

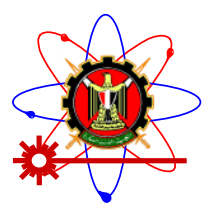

\section{$6^{\text {th }}$ International Conference on Mathematics and Engineering Physics (ICMEP-6)}

theoretic approach, Fuzzy Sets and Systems 52 (1992) 39-45.

[11] J.S.H. Kornbluth, R.E. Steuer, Multiple objective linear fractional programming, Management Science 27 (1981) 1024- 1039

[12] J.S.H. Kornbluth, R.E. Steuer, Goal programming with linear fractional criteria, European Journal of Operational Research 8 (1981) $58-65$.

[13] Y.J Lai, Hierarchical optimization. A satisfactory solution. Fuzzy Sets and Systems 77 (1996) 321335.

[14] E. S. Lee and Hsu-shih Shih, Fuzzy and Multi-Level Decision Making An Interactive Computational Approach, Springer-Verlag London limited, 2001.

[15] M.K. Luhandjula, Fuzzy approaches for multiple objective linear fractional optimization, Fuzzy Sets and Systems 13 (1984) 11-23.

[16] R.H. Mohamed, The relationship between goal programming and fuzzy programming, Fuzzy Sets and Systems 89 (1997) 215-222.

[17] B. N. Moitra, B. B. Pal, A Fuzzy Goal Programming Approach for Solving Bilevel Programming Problems, N.R. Pal and M Sugeno (Eds.): AFSS 2002, LNAI 2275, pp. 91-98, 2002., Springer-Verlag Berlin Heidelberg 2002.

[18] M. S. Osman, M. A. Abo-Sinna, A . H. Amer, and O. E . Emam, Interactive Decision-Making for Three-Level Multi-Objective Non-linear Programming Problem, The 38th Annual conference on Statistics, Computer Sciences and Operation Research 13-16 Dec. (2003) 95-110.

[19] M. S. Osman, M. A. Abo-Sinna, A . H. Amer, and O. E . Emam, A Multi-Level Nonlinear MultiObjective Decision Making Under Fuzziness, Journal of Applied Mathematics and Computation 153 (2004) 239-252.

[20] B. B. Pal, Bhola Nath Moitra, Ujjwal Maulik, A goal programming procedure for fuzzy multiobjective linear fractional programming problem, Fuzzy Sets and Systems 139 (2) (2003) 395-405.

[21] B. B. Pal, B. N. Moitra, A fuzzy goal programming procedure for solving quadratic bilevel programming problems, International Journal of Intelligent Systems 18 (5) (2003) 529-540.

[22] B.B. Pal, I. Basu, A goal programming method for solving fractional programming problems via dynamic programming, Optimization 35 (1995) 145-157.

[23] S. Pramanik, T. Kumar Roy , Fuzzy goal programming approach to multilevel programming problems, European Journal of Operational Research 176 (2006) 1151-1166.

[24] Ue Pyng and Sen-Fon Lin, Fining an Efficient Solution to Linear Bi-Level Programming Problem: An Efficient Approach, Journal of Global Optimization 8 (1996) 295-306.

[25] M. Sakawa, Fuzzy sets and Interactive Multiobjective Optimization, Plenum Press New York, 1993.

[26] X. Shi and H. Xia, Interactive Bi-Level Multi-Objective Decision Making, Journal of the Operational Research Society, 48 (1997) 943-949.

[27] X. Shi and H. Xia, Model and Interactive Algorithm of Bi-Level Multi-Objective with Multiple Interconnected Decision Makers, Journal of Multicriteria Decision Analysis 10 (2001) 27-34.

[28] H.S. Shih, Y.J. Lai and E.S. Lee, Fuzzy approach for multi-level programming problems, Computers and Operations Research 23(1) (1996) 73-91.

[29] S. Sinha, Fuzzy mathematical programming applied to multi-level programming problems, Computers and Operations Research30 (2003) 1259-1268.

[30] S. Sinha, Fuzzy programming approach to multi-level programming problems, Fuzzy Sets and Systems 136 (2003) 189-202.

[31] R. E. Steuer, Multiple Criteria Optimization: Theory, Computations, and Applications, Willy \& Sons, New York, 1986.

[32] L. N. Vicent and P.H. Calamai, Bilevel and Multilevel Programming: A Bibliography Review, Journal of Global Optimization 5 (1994) 291-306.

[33] L. A. Zadeh Fuzzy sets. Inform. Control 8 (1965) 338-353.

[34] H-J. Zimmermann, Fuzzy programming and linear programming with several objective functions, Fuzzy Sets and Systems 1 (1978) 45-55. 